\title{
RAZPRAVE
}

\section{POGOSTOST IN OBSEG POŽAROV V NARAVI NA KRASU IN V SLOVENSKI ISTRI}

\author{
AVTORICI \\ mag. Diana Veble \\ Gabrje pri Dobovi 49, SI - 8257 Dobova, Slovenija \\ diana.veble@gmail.com \\ dr. Valentina Brečko Grubar \\ Univerza na Primorskem, Fakulteta za humanistične študije, Titov trg 5, SI - 6000 Koper, Slovenija \\ valentina.brecko.grubar@fhs.upr.si
}

DOI: $10.3986 / G V 88101$

UDK: 911.2:630^43(497.472)

COBISS: 1.01

\section{IZVLEČEK}

\section{Pogostost in obseg požarov v naravi na Krasu in v slovenski Istri}

Kras in slovenska Istra, ki sta del Kraškega gozdnogospodarskega območja sta poznana po pogostih požarih $v$ naravnem okolju. Prispevek predstavlja rezultate raziskave o pogostosti požarov v naravi v obdobju 1995-2012, njihovi razporeditvi po mesecih ter o obsegu opožarjenih zemljišč. Ugotovili smo, da so bila leta $z$ nadpovprečnim številom požarov pogostejša $v$ zadnjem desetletju, da je mesec $z$ največ požari marec ter da v letih z največ požari niso nujno najobsežnejša tudi opožarjena zemljišča. Za leta z največ požari in največjim obsegom opožarjenih zemljišč smo pregledali vremenske razmere ter ugotovili, da so bila to leta s podpovprečno količino padavin in daljšimi sušnimi obdobji.

\section{KLJUČNE BESEDE}

požari v naravi, požarna ogroženost, opožarjena zemljišča, Kraško gozdnogospodarsko območje, Kras, slovenska Istra

\begin{abstract}
The frequency and extent of wildfires on the Kras and in Slovenian Istria

The Kras and Slovenian Istria, which are both within the »Kras forest management area", are known for frequent fires in nature. The study presents the results of a research into the frequency of wildfires from 1995 through 2012, their occurrence by months, and the extent of burnt areas. It was discovered that the years with the above-average number of fires are more numerous in the last decade; that March is the month with the greatest number of fires; and that the years with the most extensive burnt areas do not necessarily coincide with the years with the greatest number of wildfires. Weather conditions were surveyed for the years with the greatest occurrence of fires and those with the largest extent of the burnt areas. It was established that these were the years with below-average precipitation and longer dry periods.
\end{abstract}

KEY WORDS

wildfires, fire risk, burnt areas, Kras forest management area, Kras, Slovenian Istria

Uredništvo je prispevek prejelo 4. decembra 2015. 


\section{Uvod}

Kraško gozdnogospodarsko območje (GGO Kras) obsega Kras, Brkine z dolino Reke, Čičarijo, Podgorski kras in Podgrajsko podolje ter Vipavska in Koprska (Šavrinska) brda z obalnim pasom. Skupaj obsega 152.463,48 ha in je razdeljeno v deset gozdnogospodarskih enot, ki se po naravnih lastnostih precej razlikujejo (Gozdnogospodarski ... 2012). Za Kraško gozdnogospodarsko območje je značilen gričevnat in uravnan planotast relief $\mathrm{z}$ vmesnimi dolinami; izmenjujeta se fliš in apnenec ter posledično rečno-denudacijski in kraški relief. Prevladujoče je obsredozemsko podnebje. Med flišna območja spadajo slovenska Istra, Vipavska brda in Brkini z reko Reko, med kraška pa Kras, Podgorski kras, Čičarija s Podgrajskim podoljem in del zgornje Pivke. Na območju prevladuje zaledno obsredozemsko podnebje s srednjimi letnimi temperaturami pod $12{ }^{\circ} \mathrm{C}$, januarskimi od 0 do $4{ }^{\circ} \mathrm{C}$ in julijskimi od 20 do $22^{\circ} \mathrm{C}$. Letna količina padavin se giblje od 1000 do $1500 \mathrm{~mm}$ in so, v primerjavi s sredozemskim podnebjem, bolj enakomerno razporejene. Največ padavin je v jeseni, najmanj pa na prehodu zime v pomlad in poleti. Najbolj sušni mesec je julij (Ogrin s sodelavci 2012). Kljub omenjeni enakomernejši razporeditvi padavin, pa se poleti pogosto pojavlja njihovo pomanjkanje in sušnost, kar vpliva na pogostost požarov v naravnem okolju. Visoke poletne temperature namreč vplivajo na veliko izhlapevanje. Zaradi prepustne kamninske zgradbe in tanjše prsti so sušnosti še zlasti izpostavljena območja na apnencu. Na slabše prepustnih flišnih kamninah je prst debelejša in zadrži več vode, kar se odraža v nižji požarni ogroženosti flišnih območij.

Na Kraško gozdnogospodarskem območju prevladujejo naravne združbe listnatih gozdov, predvsem termofilnih hrastovih gozdov ter termofilnih in mezofilnih bukovih gozdov. Ti skupaj predstavljajo $88,9 \%$ vseh gozdov. Gozdne sestoje, ki se razlikujejo od naravnih, je oblikovalo gospodarjenje z gozdovi in pogozditev Krasa s črnim borom. Trajnim travnikom je v letu 2012 pripadalo malo manj kot $20 \%$ zemljišč, vinogradom, njivam in oljčnikom skupaj dobrih $5 \%$, kar 60,1\% zemljišč pa je bilo pod gozdom. V prihodnjem desetletju bo poraslost z gozdom še večja, če h gozdnatosti prištejemo $2,6 \%$ zemljišč v zaraščanju in 4,5\% kmetijskih zemljiščc, poraslih z gozdnim drevjem ter drevesi in grmičevjem. Vse večje zaraščanje in ogozdovanje je tudi pomembno prispevalo k večji ogroženosti območja s požari v naravi. Kraško gozdnogospodarsko območje se namreč uvršča med najbolj požarno ogrožena območja v Sloveniji in znotraj njega še zlasti gozdnogospodarski enoti Kras I in Kras II, ki sta večinoma uvrščeni v prvo stopnjo požarne ogroženosti (slika 1; Gozdnogospodarski ... 2012).

\section{Metodologija}

V raziskavi smo analizirali podatke Območne enote Sežana Zavoda za gozdove Slovenije in Uprave Republike Slovenije za zaščito in reševanje, ki so se nanašali na število požarov v naravnem okolju ter obseg požarišč v obdobju 1995-2012. Na podlagi analize uporabljenih podatkov smo ugotovili razporeditev požarov po mesecih in letih ter velikost opožarjenih zemljišč. Tako smo izbrali leta in mesece, v katerih sta bila število požarov in površina požarišč izrazito nadpovprečna ter jih vključili v analizo podnebnih razmer.

S pomočjo podatkov, dostopnih na spletni strani Agencije Republike Slovenije za okolje, smo za izbrane klimatološke postaje na območju Kraškega gozdnogospodarskega območja ugotavljali odstopanja padavin v izbranih letih, $v$ katerih je bilo zabeleženo največje število požarov in so pogorele največje površine gozdov, od tridesetletnih značilnih vrednosti. Želeli smo namreč ugotoviti, ali so bile v letih $\mathrm{z}$ največ požari in $\mathrm{z}$ nadpovprečnim obsegom pogorelih zemljišč zabeležene podpovprečne srednje mesečne količine padavin.

Slika 1: Požarna ogroženost Kraškega gozdnogospodarskega območja (Geršič in sodelavci 2014, 107). 


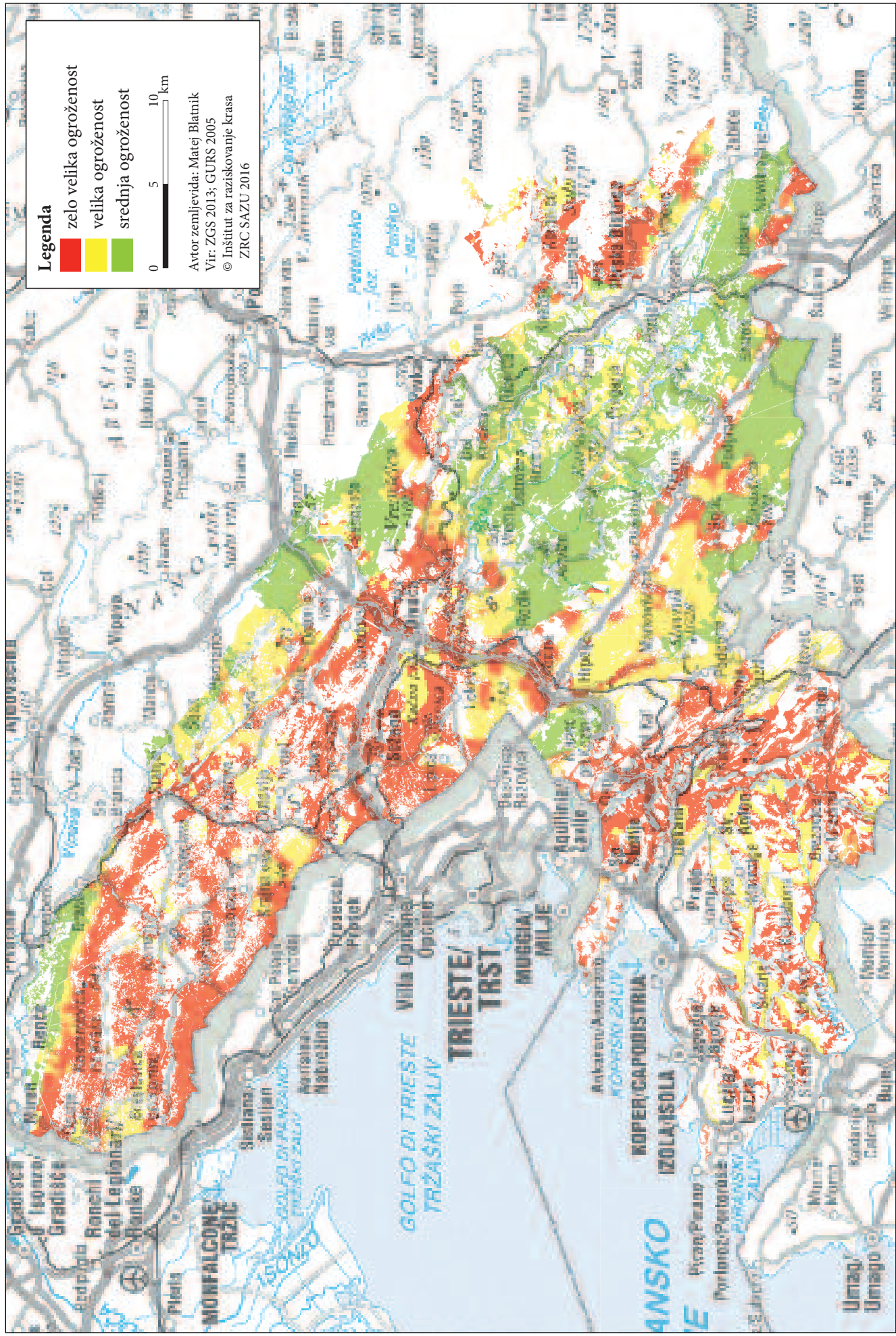




\subsection{Požarna ogroženost naravnega okolja v Kraškem gozdnogospodarskem območju}

V naravi se požari največkrat pojavijo zaradi človekove neprevidnosti in malomarnosti (na primer odprta kurišča, požiganje travišč, odlaganje odpadkov, odmetavanje cigaretnih ogorkov, namerni požigi) ter zaradi tehničnih naprav in infrastrukture (železnice, ceste, elektrovodi). Od človeka neodvisno pa se požari v naravi večinoma pojavljajo zaradi strel ob nevihtah. Širjenje ognja je rezultat okolja, v katerem se ogenj razvije. To okolje pa ustvarjajo topografija, vremenske razmere, goriva in ogenj (Jugovac 2012). Gozdne požare razvrščamo glede na mesto ognja na: podtalne, talne, vršne oziroma kompleksne, debelne in kombinirane. Najbolj pogosti požari so talni (Jakša 2006).

Na oceno požarne ogroženosti območja vplivajo naravni dejavniki, kot so (Pravilnik ... 2009): prevladujoča drevesna vrsta, starost sestojev, srednja letna temperatura, srednja letna količina padavin, srednja letna relativna vlažnost zraka, moč in pogostost vetra, periodičnost sušnih obdobij, matični substrat in vrsta tal, ekspozicija, nadmorska višina, nagib, urejenost gozdov in gozdna higiena.

Podnebne razmere nam pokažejo potencialno požarno ogroženost določenega območja, trenutne vremenske razmere in razvojna stopnja rastlinstva pa dejansko požarno ogroženost naravnega okolja. Napovedovanje dejanske požarne ogroženosti temelji na meritvah vremenskih spremenljivk na vremenskih postajah. Te spremenljivke so (Pečenko 2005): temperatura zraka, relativna vlažnost, padavine ter veter.

Meteorologi poročajo o požarni ogroženost v Sloveniji na podlagi indeksa požarne ogroženosti, kjer se požarna ogroženost izračuna na osnovi meteoroloških podatkov, ob upoštevanju razvojne stopnje rastlinstva ter stopnje verjetnosti za nastanek in širjenje požarov v naravnem okolju, ki se določi na podlagi indeksa požarne ogroženosti in statistično določenih pragov za posamezna območja (medmrežje 1).

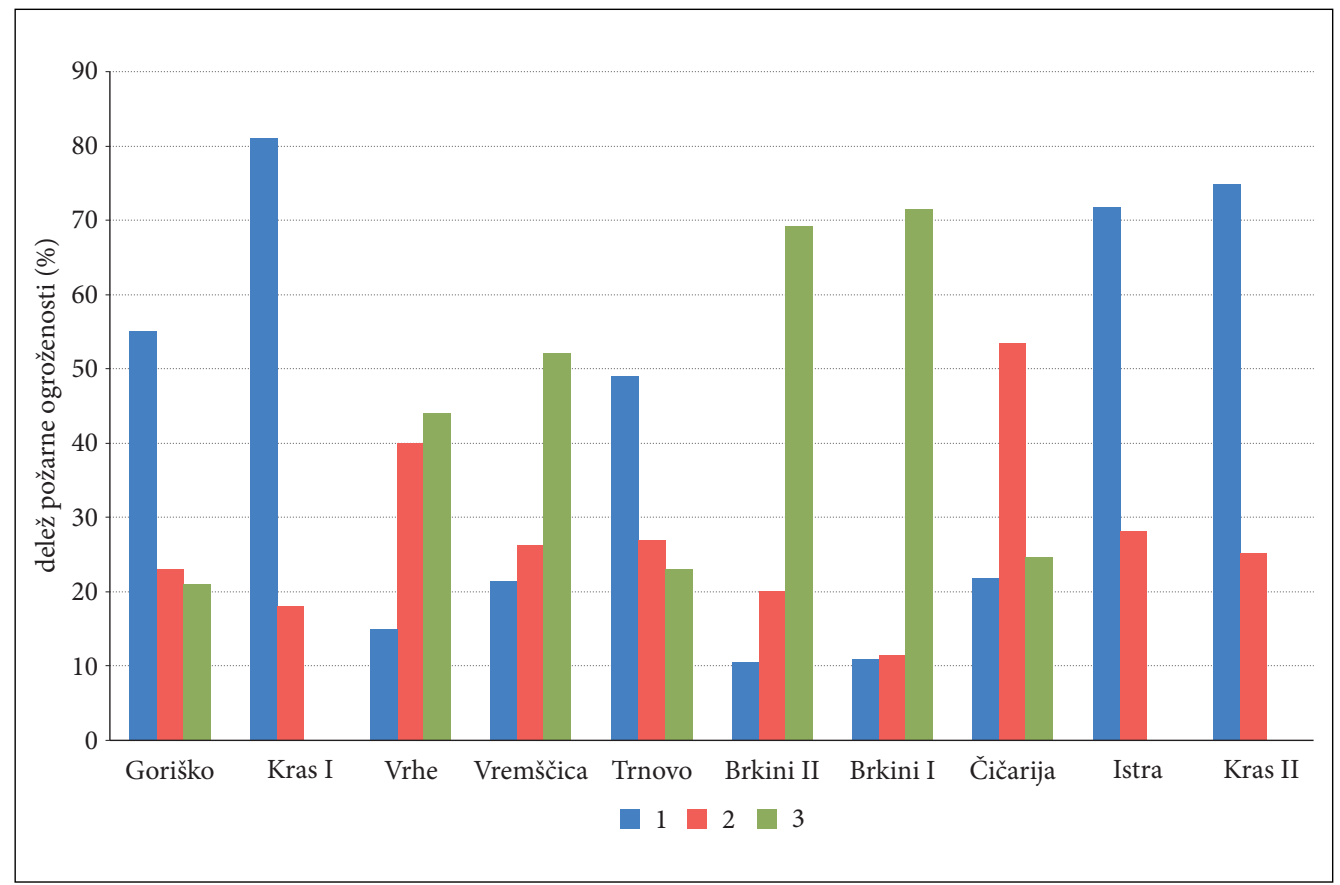

Slika 2: Stopnja požarne ogroženosti po gozdnogospodarskih enotah (GGE) v deležih (Gozdnogospodarski... 2012). 
Gozdove v Sloveniji razvrščajo po stopnji potencialne požarne ogroženosti v naslednje stopnje (Pravilnik ... 2009):

- prva stopnja ogroženosti: zelo velika ogroženost,

- druga stopnja ogroženosti: velika ogroženost,

- tretja stopnja ogroženosti: srednja ogroženost,

- četrta stopnja ogroženosti: majhna ogroženost.

Da je območje GGO Kras izpostavljeno kot požarno nadpovprečno ogroženo območje v Sloveniji, je razlog v obdobno suhem in zelo toplem obsredozemskem podnebju, v razširjenosti degradiranih rastišč, tudi zaradi preteklih požarov, prepustni kamninski zgradbi in prsti ter rastju.

V kraških in flišnih pokrajinah jugozahodne Slovenije je najmanjša količina padavin v obdobju, ko je intenzivnost Sončevega obsevanja največja in so temperature najvišje. Če v poletnem obdobju izdatnejše padavine izostanejo, rastlinstvo prizadene fiziološka suša (Geršič in sodelavci 2014).

Najbolj požarno ogrožena v Kraškem gozdnogospodarskem območju je Gozdnogospodarska enota (GGE) Kras I, ki obsega 10.864 ha. V prvo stopnjo sodi kar $81 \%$ njene površine, v drugo stopnjo pa $18 \%$ (slika 2). Zelo velika požarna ogroženost je ocenjena tudi za GGE Goriška, GGE Kras II in za manjši del na območju GGE Istra.

\section{3 Število požarov in opožarjena zemljišča v naravnem okolju v obdobju 1995-2012}

V naravnem okolju GGO Kras je bilo v obdobju med 1.1.1995 in 31.12.2012 zabeleženih 1097 požarov, pogorela zemljišča pa so obsegala 7071,4 ha (preglednica 1 ). V navedenem obdobju je bilo vsako leto povprečno 61 požarov s povprečno opožarjeno površino 6,4 ha. Kar $80 \%$ vseh požarov je bilo talnih. V primerjavi z navedbami Šturma (2013) za obdobje 1995-2009, je bilo v tri leta daljšem obdobju (1995-2012) kar 226 požarov več, opožarjene površine pa so bile večje za 1024,5 ha. Kot je razvidno iz preglednice 1, izrazito prevladujejo talni požari. Največji delež drugih tipov požarov je bil v letu 2003. Pri primerjavi števila požarov in obsega opožarjenih zemljišč po letih, smo ugotovili, da sta se, tako pogostost požarov kot površina požarišč (slika 3), povečali v drugi polovici opazovanega obdobja oziroma od leta 2003 dalje.

Največ požarov se je zgodilo v letu 2003, ko je bilo kar 143 požarov ali $13,0 \%$ vseh v osemnajstletnem obdobju. Sledili sta leti 2012 s 108 ali 9,8 \% in 1998 z 92 ali 8,4\%.

Največje opožarjene površine so bile, prav tako kot število požarov, v letu 2003, ko so požari zajeli 1552 ha ali $21,9 \%$ vseh opožarjenih zemljišč v obdobju. Sledili sta leti 2006 s 1315,9 ha ali 18,6 \% in 1998 z 965,5 ha ali $13,7 \%$. Leto 2012 , ki je bilo po številu požarov na drugem mestu, se je po velikosti opožarjenih površin s 717,5 ha ali $10,1 \%$ uvrstilo na četrto mesto. Leta $\mathrm{z}$ nadpovprečnim obsegom opožarjenih zemljišč prikazuje slika 3 .

Nadpovprečno veliko požarov v navedenem obdobju je bilo v letih: 1998, 2003, 2007, 2009, 2011 in 2012. Leti 2000 in 2005 pa sta se povprečju zelo približali. Nadpovprečni obseg opožarjenih površin pa je bil zabeležen v letih: 1997, 1998, 2003, 2006 in 2012.

Domneva, da večje število požarov povzroči tudi več opožarjenih zemljišč, se ni potrdila. V letu 2006 je $6,6 \%$ vseh požarov povzročilo $18,6 \%$ vseh opožarjenih zemljišč, kar kaže na to, da je pri obsegu poškodovanih zemljišč zelo pomembna intenzivnost požara. Pri številu so v posameznih letih lahko v večji meri zastopani manj obsežni požari, $v$ drugih letih pa je požarov lahko manj, a zajamejo večje površine. Tudi manjše število požarov lahko namreč povzroči zelo veliko opožarjenih zemljišč. Primerjava med številom požarov in velikostjo opožarjenih zemljišč je razvidna iz slike 3.

Glede pogostosti požarov v GGO Kras po mesecih v obdobju 1995-2012 izstopajo februar, marec, julij in avgust (preglednica 2). Domnevali smo, da bo največje število požarov v poletnih mesecih, analiza pa je pokazala, da je to marec z 249 ali 22,7 \% vseh požarov. Na drugo mesto se je z opazno manjšim številom uvrstil avgust in sicer s 185 požari ali $16,9 \%$ in na tretje julij s 156 požari ali $14,2 \%$. Ko smo 
Diana Veble, Valentina Brečko Grubar Pogostost in obseg požarov v naravi na Krasu in v slovenski ...

Preglednica 1: Število požarov, velikost požarišč in delež talnih požarov v Kraško gozdnogospodarskem območju v obdobju 1995-2012 (vir podatkov: Šturm 2013 in Zavod za gozdove Sežana 2014).

\begin{tabular}{lcccccc}
\hline leto & $\begin{array}{c}\text { število } \\
\text { požarov }\end{array}$ & $\begin{array}{c}\text { delež } \\
(\%)\end{array}$ & $\begin{array}{c}\text { velikost } \\
\text { požarišč (ha) }\end{array}$ & $\begin{array}{c}\text { delež } \\
(\%)\end{array}$ & $\begin{array}{c}\text { število talnih } \\
\text { požarov }\end{array}$ & $\begin{array}{c}\text { delež } \\
(\%)\end{array}$ \\
\hline 1995 & 16 & 1,4 & 154,6 & 2,2 & 15 & 93,7 \\
1996 & 28 & 2,5 & 240,8 & 3,4 & 26 & 92,8 \\
1997 & 33 & 3,0 & 418,5 & 5,9 & 29 & 87,9 \\
1998 & 92 & 8,4 & 965,5 & 13,7 & 76 & 82,6 \\
1999 & 46 & 4,2 & 310,1 & 4,4 & 39 & 84,8 \\
2000 & 58 & 5,3 & 105,2 & 1,5 & 50 & 86,2 \\
2001 & 46 & 4,2 & 321,2 & 4,5 & 36 & 78,3 \\
2002 & 29 & 2,6 & 125,4 & 1,7 & 28 & 96,5 \\
2003 & 143 & 13,0 & 1552,0 & 21,9 & 115 & 80,4 \\
2004 & 46 & 4,2 & 135,0 & 1,9 & 44 & 95,6 \\
2005 & 59 & 5,4 & 141,7 & 2,0 & 58 & 98,3 \\
2006 & 72 & 6,6 & 1315,9 & 18,6 & 61 & 84,7 \\
2007 & 78 & 7,1 & 76,8 & 1,1 & 76 & 97,4 \\
2008 & 34 & 3,1 & 36,0 & 0,5 & 31 & 91,2 \\
2009 & 91 & 8,3 & 148,2 & 2,1 & 78 & 85,7 \\
2010 & 31 & 2,8 & 78,3 & 1,1 & 31 & 100,0 \\
2011 & 87 & 7,9 & 228,7 & 3,2 & 81 & 93,1 \\
2012 & 108 & 9,8 & 717,5 & 10,1 & 100 & 92,6 \\
skupaj & 1097 & 100,0 & 7071,4 & 100,0 & 874 & $/$ \\
\hline & & & & & \\
\hline
\end{tabular}

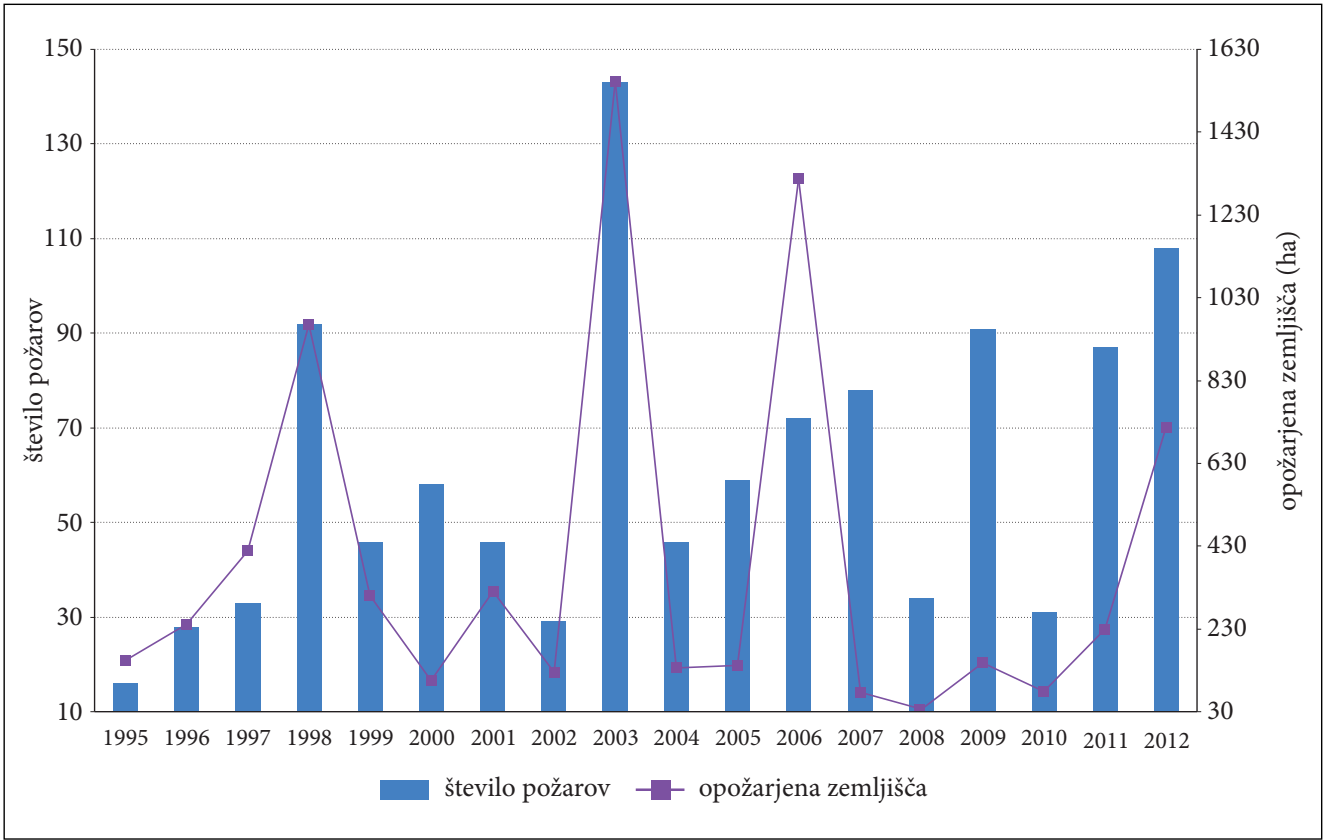

Slika 3: Število požarov in opožarjena zemljišča v GGO Kras v obdobju 1995-2012. 
združili mesece v meteorološke letne čase, smo ugotovili, da sta pomlad in poletje po deležu požarov enakovredna. V pomladnih mesecih je bilo $37,8 \%$ vseh požarov, v poletnih pa $37,4 \%$. Najmanj požarov je $v$ jesenskih mesecih od (septembra do novembra) $(6,8 \%)$, ko je običajno največ padavin. Nekoliko več jih je v sušnejših zimskih mesecih od decembra do februarja (17,6\%).

Preglednica 2: Pogostost požarov in površine požarišč po mesecih v obdobju 1995-2012 v GGO Kras (Šturm 2013; Zavod za gozdove Sežana 2014).

\begin{tabular}{lrrrc}
\hline mesec & število požarov & delež (\%) & površina požarišč (ha) & delež (\%) \\
\hline januar & 40 & 3,6 & 194,4 & 2,7 \\
februar & 137 & 12,5 & 558,3 & 7,9 \\
marec & 249 & 22,7 & 1109,4 & 15,7 \\
april & 103 & 9,4 & 1071,9 & 15,2 \\
maj & 63 & 5,7 & 134,7 & 1,9 \\
junij & 69 & 6,3 & 124,9 & 1,8 \\
julij & 156 & 14,2 & 2603,3 & 36,9 \\
avgust & 185 & 16,9 & 934,6 & 13,2 \\
september & 59 & 5,4 & 80,6 & 1,1 \\
oktober & 15 & 1,4 & 65,8 & 0,9 \\
november & 5 & 0,4 & 5,7 & 0,08 \\
december & 16 & 1,4 & 186,5 & 2,6 \\
skupaj & 1097 & 100,0 & 7070,1 & 100,0 \\
\hline
\end{tabular}

Opožarjene površine so bile največje v poletnih $(51,9 \%)$ in pomladnih mesecih $(32,8 \%)$; v zimskih mesecih so obsegale $13,2 \%$, v jesenskih pa le $2,9 \%$. Omenili smo, da sta glede pogostosti požarov pomlad in poletje enakovredna. Podatki pa kljub temu kažejo odstopanje v površini požarišč, kar kaže na to, da so požari v pomladnih mesecih manj intenzivni in jih je lažje omejiti oziroma pogasiti. Največje opožarjene površine so bile julija (36,9\%), kar je, poleg manjše količine padavin, gotovo tudi odraz višjih temperatur in intenzivnega izhlapevanja. V marcu so bile opožarjene površine za več kot polovico manjše (15,7\%), presenetljivo pa se je na tretje mesto uvrstil april (15,2\%), ki ga sicer povezujemo z nestanovitnim vremenom ter pogostejšimi padavinami. Število požarov je bilo aprila manjše v primerjavi $z$ avgustom, ki se je s 13,2 \% opožarjenih površin uvrstil na četrto mesto. Najmanjša požarna aktivnost je bila zabeležena od oktobra do januarja.

\section{Vremenske razmere $\mathrm{v}$ letih $\mathrm{z}$ največjim številom požarov}

Kot rečeno je bilo v GGO Kras v obdobju 1995-2012 največje število požarov v letih: 1998, 2003 in 2012. Sklepali smo, da so bili pogostejši požari pogojeni z manjšo količino padavin, zato smo za izbrana leta primerjali mesečne višine padavin $\mathrm{z}$ dolgoletnim povprečjem 1971-2000. Padavinske podatke smo analizirali za tri klimatološke postaje, za katere smo menili, da zadovoljivo prikazujejo razmere v različnih delih preučevanega območja. Za območje slovenske Istre smo izbrali postajo Portorož-letališče, za flišno hribovito zaledje z Brkini postajo Ilirska Bistrica in za Kras postajo Bilje pri Novi Gorici. Analiza podatkov je potrdila naše sklepanje, da so bile v letih z največ požari in največjo površino požarišč pogosto zabeležene podpovprečne mesečne višine padavin. Leta 2003 je bila višina padavin za $32 \%$ nižja od povprečne letne višine v obdobju 1971-2000 na klimatološki postaji Bilje, za 19,4 \% na klimatološki postaji Portorož-letališče in za 24,6 \% na klimatološki postaji Ilirska Bistrica. Zlasti meseci marec, maj, junij, julij in avgust so bili zelo sušni. 
Leta 2012 je bila višina padavin za 4,8 \% nižja od povprečja v obdobju 1971-2000 na klimatološki postaji Bilje, za $26 \%$ na klimatološki postaji Portorož-letališče in za 14,4\% na klimatološki postaji Ilirska Bistrica. Meseci februar, marec, julij in avgust so bili zopet zelo sušni.

Leta 1998 je višina padavin manj odstopala od dolgoletnega povprečja (1971-2000) in je bila celo za $10,9 \%$ višja na klimatološki postaji Bilje, na drugih dveh pa malo nižja (za $4,4 \%$ na postaji Portorož-letališče in za 5,8 \% na postaji Ilirska Bistrica). Sušna sta bila le februar in marec. Na sliki 4 vidimo, da je bila na postaji Bilje zabeležena višina padavin $v$ večini mesecev podpovprečna. Najdaljše obdobje podpovprečnih padavin je vedno predstavljala zima; za leto 2003 tudi poletje. Leta 1998 je februarja padlo le $0,4 \%$ običajnih padavin in marca $19,3 \%$. Padavinski primanjkljaj je bil zato izjemno visok. Leta 2003 je bila prva polovica leta padavinsko skromna, marca je padlo le $1,4 \%$ običajnih mesečnih padavin, maja $26,8 \%$, junija $24,4 \%$ in julija $34,8 \%$.

Na klimatološki postaji Portorož-letališče je bila zabeležena višina padavin v večini mesecev podpovprečna (slika 5). Najdaljše obdobje podpovprečnih mesečnih padavin predstavlja zima, za leti 2003 in 2012 tudi poletje. Najbolj sušen mesec v vseh treh izbranih letih je marec. Leta 1998 je marca padlo le $0,9 \%$ običajnih mesečnih padavin, leta $20036,3 \%$ in 2012 le $0,1 \%$. Izrazito podpovprečne padavine so bile tudi v juliju $2003(23,4 \%)$ in 2012 (11,9\%).

Podobno kot na klimatoloških postajah Bilje in Portorož-letališče je bila tudi na klimatološki postaji Ilirska Bistrica višina padavin v večini mesecev podpovprečna (slika 6), a obstaja razlika glede letnega časa. Najdaljše obdobje podpovprečnih padavin predstavlja tu poletje in le za leto 1998 tudi zima. Leta 1998 je februarja padlo 4,1 \% običajnih mesečnih padavin in marca 16,0\%. Leta 2003 so bile podpovprečne padavine od februarja do oktobra, $v$ ostalih treh mesecih pa le malo nad povprečjem. Marca je padlo najmanj in sicer le 2,7 \% običajnih mesečnih padavin. Leta 2012 je bilo manj padavin od povprečja že januarja, marca pa je padlo le $2,6 \%$ in julija $18,9 \%$ običajnih mesečnih padavin v obdobju 1971-2000.

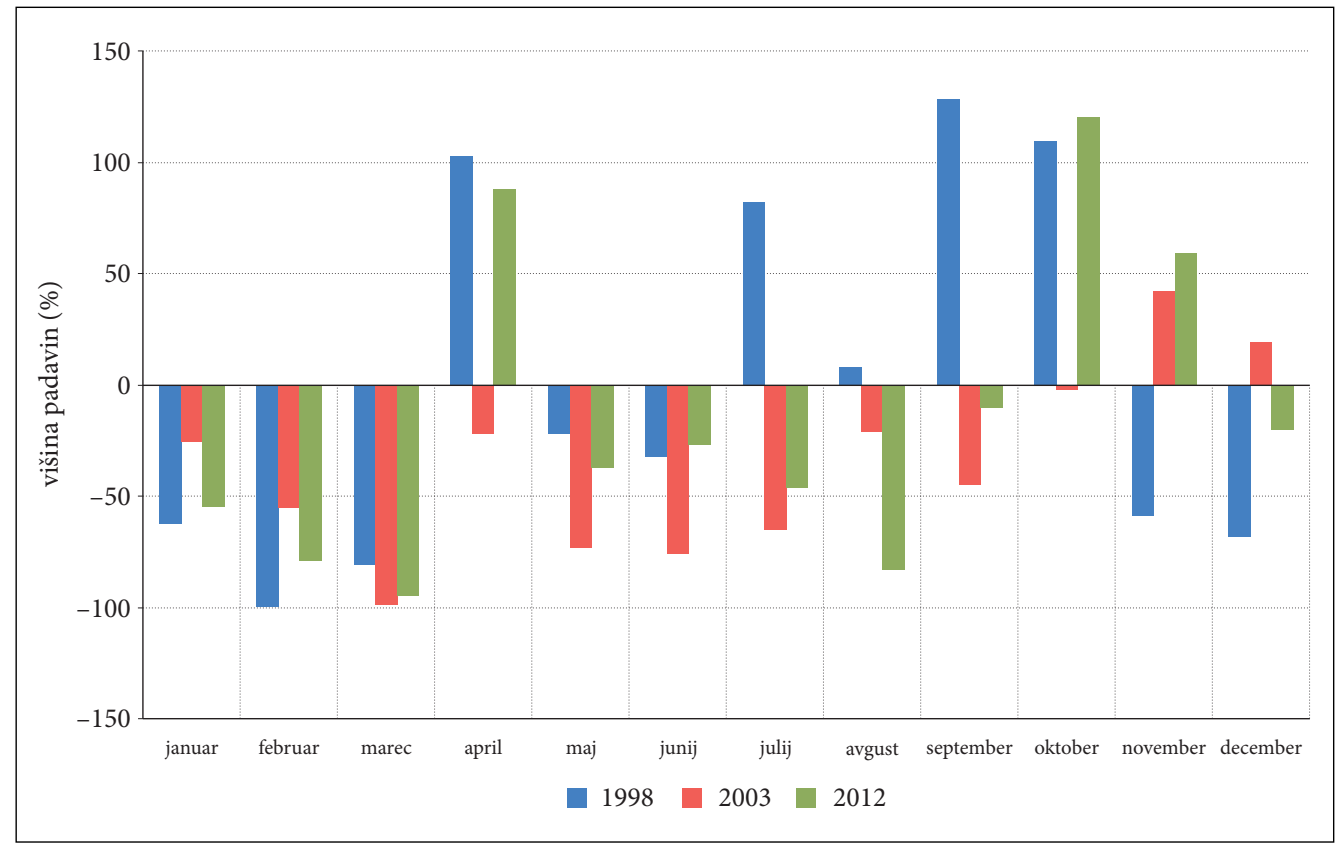

Slika 4: Odstopanje mesečnih višin padavin v letih 1998, 2003 in 2012 od dolgoletnega povprečja (1971-2000) na klimatološki postaji Bilje (medmrežje 1). 


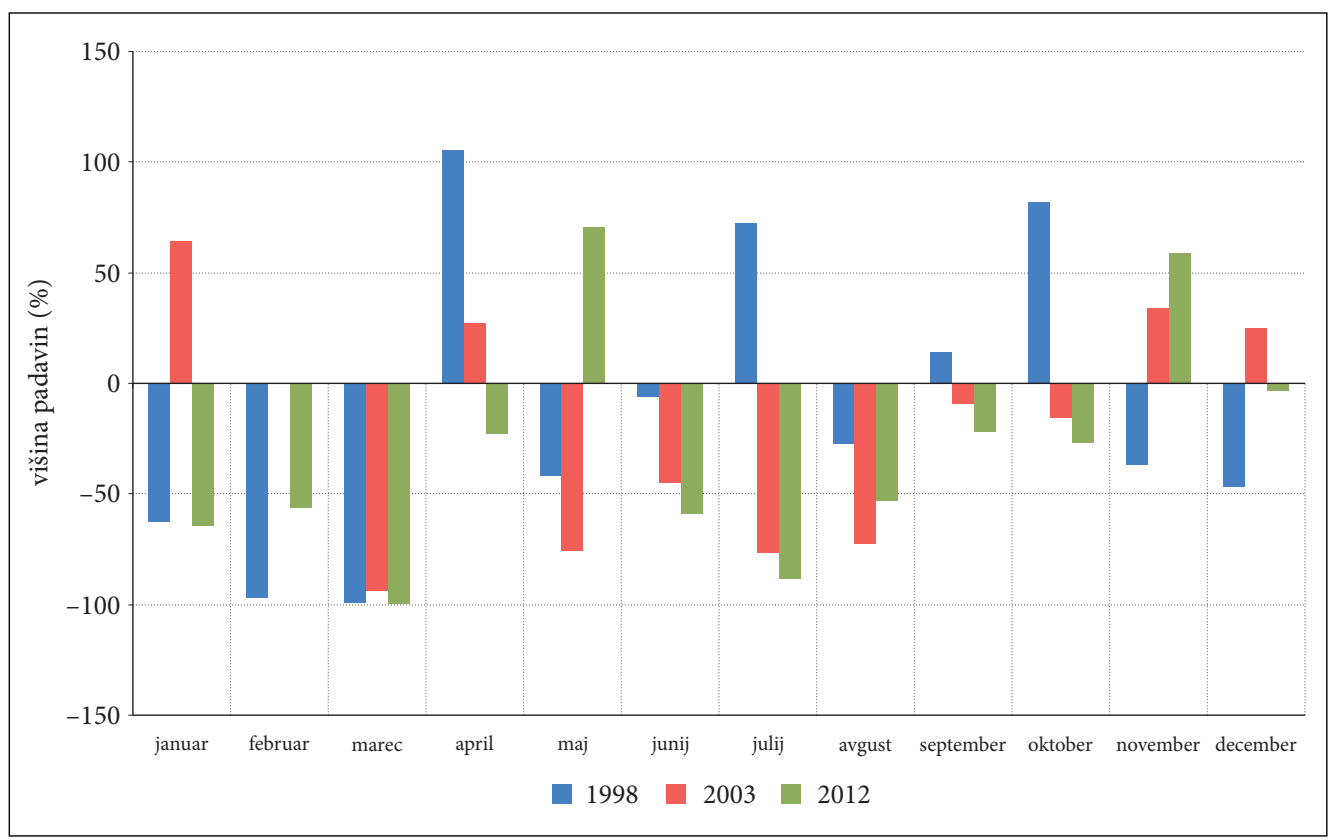

Slika 5: Odstopanje mesečnih višin padavin v letih 1998, 2003 in 2012 od dolgoletnega povprečja (1971-2000) na klimatološki postaji Portorož-letališče (medmrežje 1).

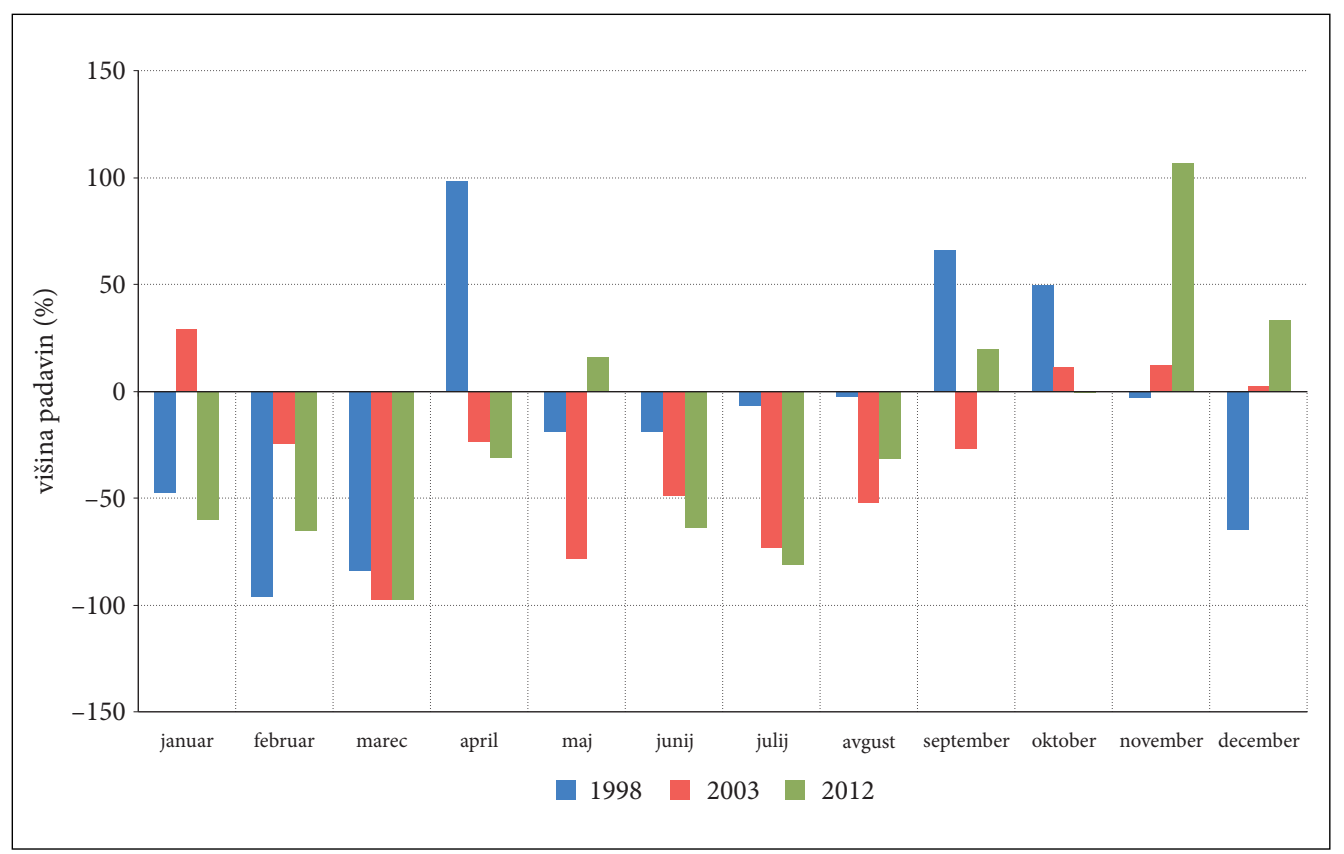

Slika 6: Odstopanje mesečnih višin padavin v letih 1998, 2003 in 2012 od dolgoletnega povprečja (1971-2000) na klimatološki postaji Ilirska Bistrica (medmrežje 1). 


\section{Sklep}

Število požarov v naravi in velikost opožarjenih zemljišč v GGO Kras v obdobju 1995-2012 sta potrdila veliko požarno ogroženost naravnega okolja. Ugotovili smo, da sta se tako število požarov kot velikost opožarjenih zemljišč po letu 2003 zelo povečala. Da so po številu požarov najbolj izstopala leta z izrazito podpovprečno višino mesečnih padavin, so pokazale primerjave višine mesečnih padavin za izbrana leta $\mathrm{z}$ dolgoletnim povprečjem. Razporeditev mesečnih višin padavin in njihovo odstopanje od povprečja, je potrdilo domnevo, da je količina padavin najpomembnejši dejavnik požarne ogroženosti.

Največ požarov v naravnem okolju nastane marca, sledita mu pa julij in avgust. To so meseci, ko je količina padavin že sicer skromna, analiza pa je pokazala, da lahko mesečne višine padavin še bistveno bolj odstopajo od srednjih vrednosti. V letih z izstopajočim številom požarov so na klimatoloških postajah zabeležili podpovprečne mesečne višine padavin tudi v mesecih, ki sicer ne veljajo za »sušne«. Za večjo intenzivnost požarov in s tem večje opožarjene površine pa poleg skromnih padavin ter sušnosti vplivajo tudi visoke temperature in s tem pogojeno večje izhlapevanje. Prsti in organski odpad v gozdu so zato izsušeni, rastlinstvo je dehidrirano in gorljivost se poveča. Najbolj obsežne opožarjene površine v preučenem obdobju so bile namreč v poletnih mesecih (julij in avgust) in tudi po površini največji požari (na primer pri Komnu na Krasu, na Sveti gori pri Novi Gorici, nad Črnim Kalom) so nastali poleti (Veble 2015). Da velika opožarjena zemljišča niso nujno posledica velikega števila požarov, so pokazali podatki za leto 2006. Da veliko število požarov ne povzroči vedno zelo obsežnih opožarjenih zemljišč, so pokazali tudi podatki za leta 2007, 2009 in 2011.

S podnebnimi spremembami, ki se kažejo v višjih temperaturah in zniževanju padavin, zlasti spomladi in poleti, se tudi na Krasu (Ogrin 2014) povečuje požarna ogroženost. Ob tem lahko poskrbimo, da zmanjšamo možnosti za nastanek požarov, saj je človek najpogostejši krivec. V prvi vrsti je nujno opozarjanje na požarno ogroženost, ozaveščanje in izobraževanje prebivalcev glede ravnanja z ognjem. Pomembno je tudi preventivno ravnanje, kot je na primer čiščenje ter odstranjevanje organskega odpada na območjih pogostih vžigov. Za slednje je primer Kraški rob, kjer so požari v naravi pogosto povzročeni z železniškim prometom. Ko je okolica železniške proge izsušena, za požar zadostuje že iskra, ki nastane ob zaviranju vlakov.

\section{Viri in literatura}

Jakša, J. 2006: Gozdni požari. Gozdarski vestnik 64-9.

Jugovac, S. 2012: Načrt ukrepanja Gasilske Brigade Koper ob požaru v naravnem okolju. Gasilska Brigada Koper. Koper.

Geršič, M., Repe, B., Blatnik, M., Brečko Grubar, V., Kovač, B., Povzek, N., Seifert, A. 2014: Geografija in rastlinska sukcesija - izbrani primeri iz Slovenskih pokrajin. Georitem 23. Ljubljana.

Gozdnogospodarski načrt Kraškega Gozdnogospodarskega območja 2011-2020. Območna enota Sežana Zavoda za gozdove Slovenije. Sežana, 2012.

Ogrin, D. 2014: Tendence spreminjanja podnebja po 2. svetovni vojni na jugovzhodu Krasa. Dela 41. DOI: http://dx.doi.org/10.4312/dela.41.4.81-100

Ogrin, D., Vysoudil, M., Mrak, I., Ogrin, M. 2012. Splošne in lokalne podnebne poteze. Geografija stika Tržaškega zaliva z zaledjem, GeograFF 12. Ljubljana.

Pečenko, A. 2005: Požari v naravi. Požarna ogroženost naravnega okolja. Urad za meteorologijo Agencije Republike Slovenije za okolje. Ljubljana.

Medmrežje 1: http://meteo.arso.gov.si (7.11.2015).

Pravilnik o varstvu gozdov. III. Ukrepi za varstvo gozdov pred požarom, preprečevanje poškodovanosti gozdov zaradi abiotskih dejavnikov ter blaženje podnebnih sprememb in prilagajanje nanje. 12 . člen (stopnja požarne ogroženosti). Uradni list Republike Slovenije 114/2009. Ljubljana. 
Šturm, T. 2013: Uporaba tehnologije GIS za napovedovanje pojavljanja gozdnih požarov v Sloveniji. Doktorsko delo, Fakulteta za gradbeništvo in geodezijo Univerze v Ljubljani. Ljubljana.

Veble, D. 2015: Geografska presoja ogroženosti obalno-kraškega območja s požari v naravi. Magistrsko delo, Fakulteta za humanistične študije Univerze na Primorskem. Koper.

\section{Summary: The frequency and extent of wildfires on the Kras and in Slovenian Istria}

(translated by Branka Klemenc)

Fires in nature are mainly started through human activity, but by far the most frequent natural cause occurs as lightning strikes during the storms. The spreading of fire depends on topography, weather conditions, fuel and fire. A significant role is played by the vegetation which affects the intensity of fire. Fires are classified according to the place of flame as ground, surface and canopy or complex fires. Surface fires are the most frequent ones in nature. The degree of fire risk is determined on the grounds of weather variables, such as air temperature, relative humidity, precipitation and wind. Of great importance are also the composition of vegetation, amount of plant litter in the wood, and permeability of rock basis and soil. For Slovenian forests a four-degree scale of fire risk is determined, from the first degree which means a very high risk, to the fourth which means but a low risk.

The »Kras forest management area " (GGO Kras) belongs to the area's most greatly endangered by fires in Slovenia. This is, however, due to the climate and permeable rock base. Most of the area ranks within the classes of very high and high fire risk. Prevailing in this area are plant communities of deciduous forests, mainly of thermophilic oak and thermophilic and mesophilic birch forests. Pine as a forest species prevails in one fifth of the forests. Wooded areas are increasing since pastures and meadows are being overgrown, which will add to a higher wildfire risk in the area.

From 1995 through 2012, as much as 1,097 fires occurred in the GGO Kras, in which 7,071 hectares of surface got burnt. Every year, an average of 61 fires occurred, with the average burnt area of 6.4 hectares. Data analysis shows that fires were most frequent in 1998, 2003 and 2012; the highest occurrence was in 2003 (13\% of all fires), then comes 2012 with $9.8 \%$, and 1998 with $8.4 \%$ of all fires. Also the extent of burnt areas was the largest in the above-mentioned years, only their sequence differs: 2003 (1,552 ha); 1998 (965.5 ha) and 2012 (717.5 ha). Comparison of data from the research by Šturm (2013) for the 1995-2009 period with ours for the 1995-2012 period shows that in the three additionally studied years there were 226 more fires, which is by $20.6 \%$ more than in the $1995-2009$ period, and the total extent of burnt areas increased by $1,024.5 \mathrm{ha}$, or $14.49 \%$.

After 2003, both the frequency and size of fires have increased. As to their occurrence by months, March, July and August stand out, while in view of the burnt areas, July is the worst. Data exposed the fact that a bigger number of fires do not necessarily cause a larger extent of burnt areas. The extent of affected areas depends on fire intensity, and also a smaller number of fires can leave behind extensive burnt areas.

It proceeds from the analysis of the data from weather stations that a greater number of fires and hence extensive burnt areas resulted from a longer period of below-average medium monthly precipitation or no precipitation at all.

In 2003, with the greatest number of fires and most extensive burnt areas, the annual precipitation, as compared to the average of the 1971-2000 period, was by 32\% lower at the meteorological station of Bilje, by $19.4 \%$ lower at the Portorož-airport, and by $24.6 \%$ lower at Ilirska Bistrica. The months from March through August, with the exception of April, were very dry. Also in the year 2012, the precipitation was below-average, by $4.8 \%$ at the meteorological station of Bilje, by $26 \%$ at Portorož-airport, and by $14.4 \%$ at Ilirska Bistrica. The months of February, March, July and August were very dry. The third as to the number of fires was the year 1998, when the quantity of precipitation did not significantly 
deviate from the average. Precipitation at Bilje was slightly above the average, at Portorož and Ilirska Bistrica slightly below the average. February and March were dry.

In addition to precipitation deficit on the annual level, the uneven precipitation distribution or longer spans without precipitation are most crucial for fire risk. All of the most extensive fires in the GGO Kras, those at Komen on the Kras, Sveta gora at Nova Gorica and Črnotiči-Črni Kal, occurred in summer.

Contributing to greater intensity of fires in the dry summer period are also higher air temperatures, dry soil and dry organic matter (fallen branches and leaves, coniferous' leaves, grass). Overgrown areas, poorly maintained forest and the presence of coniferous trees (Pinus nigra) significantly contribute to the occurrence and spreading of fires since there is a lot of fuel available. A human is also an important factor of fire occurrence, therefore it is of utmost importance to call attention to fire risk, make people aware of this fact and exercise preventative activities. 